\title{
Engineering Education and Learning outside the Classroom through MOOCs: Student Assessment
}

\author{
Olga Tarasova ${ }^{1}$, Aleksei Bykov ${ }^{2}$, Tetiana Likhouzova ${ }^{3}$, Irina Petunina ${ }^{4}$ \\ ${ }^{1}$ Nizhny Novgorod Dobrolyubov State Linguistic University, Nizhny Novgorod, Russian Federation \\ ${ }^{2}$ Moscow Technical University of Communications and Informatics, Moscow, Russian Federation \\ ${ }^{3}$ National Technical University of Ukraine "Igor Sikorsky Kyiv Polytechnic Institute", Kyiv, Ukraine \\ ${ }^{4}$ Federal State Budgetary Educational Institution of Higher Education "Kuban State Agrarian University \\ named after I.T. Trubilin", Krasnodar, Russian Federation
}

\begin{abstract}
The development of engineering students is more often associated with classroom learning, but there is an increasing need for online learning. This study tests students' impressions of a specialized massive open online course. Engineering students from the Russian Federation and Ukraine $(n=295)$ were involved to the empirical part. According to the results, $84 \%$ of the participants had difficulty in using the knowledge gained during the course. In this paper, the authors suggest ways of improving online courses for students so that what they learn can be put into practice. On average, it will take universities 4.5 - 8 years to completely switch from face-to-face classes to the use of MOOCs.
\end{abstract}

Keywords - engineering education; MOOCs; technologies in education; online learning environments.

DOI: 10.18421/TEM111-59

https://doi.org/10.18421/TEM111-59

Corresponding author: Tetiana Likhouzova, National Technical University of Ukraine "Igor Sikorsky Kyiv Polytechnic Institute", Kyiv, Ukraine.

Email: tetlikhouzova@rambler.ru

Received: 24 November 2021.

Revised: 15 February 2022.

Accepted: 21 February 2022.

Published: 28 February 2022.

(c) BY-NC-ND (C) 2022 Olga Tarasova et al; published by UIKTEN. This work is licensed under the Creative Commons Attribution-NonCommercial-NoDerivs 4.0 License.

The article is published with Open Access at https://www.temjournal.com/

\section{Introduction}

Today, in the context of rapidly developing technologies and the COVID-19 pandemic, online platforms (for example, Moodle, iSpring Learn, WebTutor, Teachbase, Memberlux, etc.) are being increasingly often used in education. Engineering education is no exception. Many universities have already started using such platforms to teach their students, but there are still many problems with this (lack of technical skills, slow Internet connection, old gadgets, etc.).

Many educational institutions have done a great job of incorporating digital tools into their online courses and hybrid learning that combines a personalized approach with online learning. However, today the introduction of technology into higher education, where it is most needed, is characterized by a slow pace [1]. Universities in different countries, including the USA, the Russian Federation and Ukraine, are trying to solve this issue.

Online courses, which provide different categories of students with the opportunities to obtain new knowledge and skills or improve the ones they have, have become very popular. Nowadays, massive open online courses (MOOCs) allow learners to acquire knowledge remotely. MOOCs can be used in any area of learning. The motivation of students plays an important role. Only $15 \%$ of students who start a course complete it. At the same time, the number of students who paid their tuition fees and completed the course is much higher than the number of those who enrolled in the course free of charge and dropped out, which indicates the higher motivation of the former. The most popular MOOCs are Coursera, Future Learn, Lectorium, EdX, Open Education, Intuit and others [2]. In some cases (for example, to study a foreign language), various messengers can be used, for exam le WhatsApp [3]. 
Online platforms offer a number of advantages, for example, learning at a convenient time and from any location, reducing the cost of transport and living in another city, reducing teaching load, etc.

Today, online learning is being widely implemented and the quality of the systems required is an urgent problem. The quality of an online system, which refers to the availability and quality of content, is the most significant external factor that affects perceived ease of use and perceived usefulness. Technical students also believe that elearning platforms help them learn as they can revisit what they have already learned (tapes and videos) in an online course [4].

The use of online platforms is gaining momentum today, so it is important to carefully consider the quality of their content and the opportunities provided to students. This study aims to assess the capabilities and test the quality of online courses in the context of teaching engineering students.

\subsection{Literature Review}

Engineering and science education is generally based on skill development and content learning. However, in order to qualitatively prepare students for modern life, it is also necessary to develop critical thinking and stimulate thoughts on how to improve current practices with the help of new technologies and tools [5].

In the online learning environment, it is necessary to take into account different approaches to teaching engineering disciplines. Content-based learning consists of sequential teaching of basic concepts and regular lab classes. Problem-based learning refers to technical skills (such as system design and problem statement) and soft skills (such as teamwork, communication skills, lifelong learning, and professional (or ethical) responsibility) [6]. Active learning is a broad concept that refers to educational approaches aimed at student participation rather than passive listening. There are many approaches to active learning, including problem-based learning, project-based learning, challenge-based learning, service learning, flipped teaching, gamification, and game-based learning [7].

The collaboration model described by the Spanish researchers is based on the peer review methodology, which is implemented on an online learning platform. The students were asked to review the work of their fellow students, namely, to suggest ways to improve, comment on, and evaluate the tasks completed. The process was supervised by the teachers. The experiment was attended by the Faculty of Computer Science students. According to the results, content mastery and several skills improved. Although the team performance was greater than that of an individual student, the researchers cannot conclude that there was genuine collective intelligence. According to them, ICT-based teaching methodologies offer new methods of knowledge transfer and management in higher education. The fact that students collaborate in evaluating each other's work contributes to their motivation and promotes an active learning process [5].

\subsection{Virtual Laboratories}

Virtual laboratory is a source of information that provides students with the opportunity to master practical skills and allows them to simulate environmental phenomena and processes. The advantages of a virtual laboratory involve reducing the amount of equipment for experiments, improving the visibility of experiments in the absence of appropriate equipment at the university, developing students' thinking skills using new Internet technologies, improving the quality of information support for the learning process, automating the verification of student experiment results, reducing the risk of injury (for example, burns). The disadvantage of a virtual laboratory is the lack of tactile sensations during experiments. In general, virtual laboratories were created not to replace real experiments but to supplement them [8].

Available online laboratories have different interfaces and technical settings ranging from a simple experimental room based on a webcam to complex direct control and feedback systems. Some of them have been integrated into the learning environment while others have a separate application programming interface. Today the most popular online labs are RoboticHomeLabkit test bench, Mobile robotlab, Manipulatorlab, 3D printerLab [9].

\subsection{Forums}

Internet forums are a good platform for students to communicate and learn, but the problems related to finding and tracking a large amount of data that are generated on them often has the opposite effect. Scientists suggest computer processing of information that can be used in online learning. Thus, information is processed using human language processing techniques and the main topics of discussion are identified. According to the researchers: (1) Forums are the most important factor in the success of Open and Distance Learning (ODL); (2) Forums can improve transfer of knowledge, which will help increase participation, teach and retain learners; (3) Methods of automatic analysis of information can help process large volumes of messages [10]. 


\subsection{Massive Open Online Courses}

Today Massive Open Online Courses (MOOCs) are a tool that provides free quality education opportunities for everyone. Learners can also study engineering and programming on these platforms. However, programming cannot be mastered only with the help of common MOOC components such as content reading, video lectures, and quizzes. This requires hands-on programming exercises and timely feedback. German researchers offer automatic evaluation of programming problems. Similar systems that automatically assess students' programming assignments have been in use for over fifty years. Educational web-based tools such as Codewars and CodingBat can help educators as they already contain a collection of hands-on programming exercises that can be used in a web browser [11].

Lack of self-discipline to complete MOOCs and lack of interaction with others are the major hurdles compared to compulsory lecture attendance. Nevertheless, MOOCs offer a flexible schedule and an opportunity to study regardless of location, which makes it easier to access such education, in particular for those who want to study entrepreneurship. There are 4 main characteristics of MOOCs: (1) They are open to everyone, no entry requirements; (2) There is no limit to the number of participants; (3) They are free; (4) Courses are fully online [12].

Online courses should be evaluated according to the following criteria: instructor design; communication, interaction and collaboration; student assessment; student support and resources; web design and course evaluation [13].

\subsection{Big Data}

The advantages of big data technology in education include improved learning experience, higher-quality learning, improved market analysis, effective decision making, predictable learning and assessment strategy. Big data technology is used in education for several purposes, such as identifying students at the risk of dropping out; predicting academic performance; studying student behavior; tracking absenteeism; making course recommendations; providing instant help and assessment; ensuring visual analytics of student interaction on forums; improving accessibility; promoting research and development; identifying the risk of non-assimilation of the course by students [14].

\subsection{Engineering Student Platforms}

CooL: SLiCE Cyberlearning Platform. American scientists have created an interactive web-based cyber learning environment. Constructionism in Learning: Sustainable Life Cycle Engineering (CooL: SLiCE). It was designed to facilitate the consideration of different human-initiated or controlled impacts on the natural environment through team and individual project activities. Thus, CooL: SLiCE enables physical/hands-on engineering education based on a virtual platform that allows students to analyze and visualize changes in product design, manufacturing processes, and supply chain configurations in terms of sustainability indicators. CooL: SLiCE Cyberlearning Platform contains the modules of Product Design and Visualization; Manufacturing Process and System Analysis; Sustainable Product Architecture and Supplier Selection (S-PASS) [15].

CARDS. Online Card Sorting Platform (CARDS). CARDS enables researchers to develop card sorting tasks and send them to participants in order to remotely collect data and analyze them. A card sorting session involves participants sorting a set of cards (such as engineering scenarios) while relying on any chart that they think is appropriate. Thus, cards with car images can be sorted by color, number of doors or size, and there is no correct sorting method. This approach is often used in user interface (UX) design when users are asked to sort cards by category to get usability feedback, such as how to organize context menus [16].

Today, online education is still not very popular among students. The main factors affecting student acceptance of online learning are the learning environment, instructor availability, clear and timely feedback. Those students who prefer an online course usually focus on reducing the cost of travel to the university. Some learners believe that there are certain disciplines that they would not like to study online. Those who prefer traditional learning talk about the importance of interaction with teachers and fellow students. Some students believe that they should be taught social skills in college (university). Low motivation and technical problems were cited as other online learning problems [17].

To date, the above technologies have been poorly introduced into the educational process, but they are commonly used. 


\subsection{Setting Objectives}

Today, there is an acute problem with the quality and efficiency of online education, including engineering education. This study is conducted in order to obtain data on the quality of engineering education and the results of such training.

The purpose of the study is to determine students' learning outcomes in the context of online education, describe its advantages and disadvantages, as well as develop recommendations for improvement.

The objectives of the study include determining the quality of the online platform/course, assessing the relevance of the course and students' interest in it, as well as determining the effectiveness of the online platform in teaching engineering students.

\section{Methods and Materials}

\subsection{Research Design and Sample}

The research was based on testing and interviews. A similar method was used by Chiu and Chai [18].

\subsection{Survey}

The study was attended by 295 engineering students (19-22 years old) from Kuban State Agrarian University named after I.T. Trubilin (the Russian Federation) and Igor Sikorsky Kyiv Polytechnic Institute (Ukraine) (Table 1). They were handed out invitations in university campus facilities. The students were offered to take the online course "Systems Thinking" on the Open Learning platform. The course consists of three modules. The course topics are (1) What types of situations are we dealing with? (2) What does "complex system" mean? (3) Strengthening our systems thinking; (4) Worldview and paradigms; (5) Applying systems thinking in life. The course tasks can be completed at any time. The course lasted 3 weeks (from July 26 to August 16, 2021). After that, the participants took a written test to check the level of knowledge on the topic (August $17,2021)$ and were interviewed about their opinion on the course (August 19, 2021). The test and interviews were conducted in the classrooms of the above universities.

Table 1. Demographic information

\begin{tabular}{|c|c|c|}
\hline \multirow{2}{*}{ Gender } & Male & 160 \\
\cline { 2 - 3 } Age & Female & 135 \\
\cline { 2 - 3 } & $19-20$ & 185 \\
\hline \multirow{3}{*}{ Country } & \begin{tabular}{c} 
The Russian Federation (Kuban \\
State Agrarian University named \\
\cline { 2 - 3 }
\end{tabular} & 110 \\
\cline { 2 - 3 } & $\begin{array}{c}\text { after I.T. Trubilin) } \\
\text { Ukraine (Igor Sikorsky Kyiv } \\
\text { Polytechnic Institute) }\end{array}$ & 143 \\
\hline
\end{tabular}

Examples of test questions:

1. In what way would you like to become rich?

- Invest in my business, take risks

- Build a career in a company

- Win the lottery

2. What would you do with money if you made a million?

- Put money in the bank and receive\%

- Invest in my business

- Distribute the money between the first and second options

3. If you became rich, would you like to appear in the papers?

- My name often appears in the media

- Yes

- No

Examples of interview questions:

1. Are you interested in the topic of this course?

2. What do you think about the quality of this course?

3. Was the information easy to perceive?

4. How did you benefit from the course?

5. Would you recommend it to your friends or family?

\subsection{Data Analysis and Statistical Processing}

The test results were entered into Excel and analyzed. The interview results were recorded on a SONY voice recorder, transcribed into Word, and further analyzed as well. All the results obtained were relevant.

\subsection{Ethical Issues}

Participation in the study was voluntary. When students were invited to participate, they were handed out printed information about the objectives, rules and conditions of the study. Students' responses were not transferred to third parties and the results were not disclosed.

\subsection{Research Limitations}

The results of the study can be considered reliable as the testing procedure was supervised and the students were not allowed to use any aids but it should be noted that the participants were from only two universities in Ukraine and the Russian Federation and their number was limited. 


\section{Results}

\subsection{Test Results}

The test was aimed, first of all, not at the theoretical knowledge gained in the course but at the possibility of its practical application in real-life situations. The results showed that the majority of students $(76 \%)$ mastered the information received, but only $39 \%$ of the participants managed to effectively apply their knowledge in practice (Fig. 1).

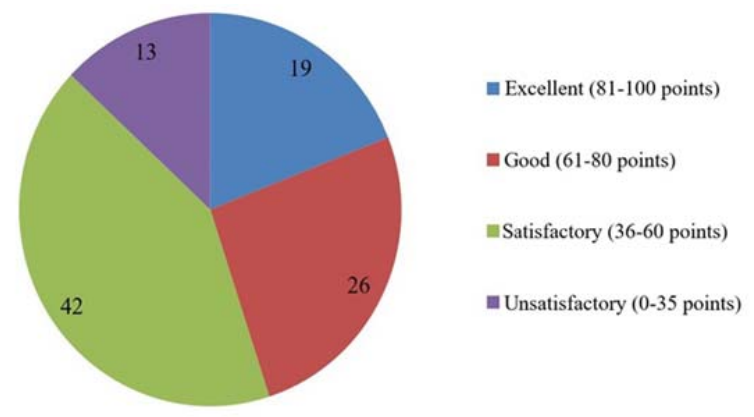

Figure 1. Students' test results, \%

As can be seen, the majority of students demonstrated "satisfactory" performance. The smallest number of students obtained "unsatisfactory" results. The performance of $32 \%$ of participants was "good" and "excellent".

The analysis of the tests showed that it is difficult for young people to grasp the situation, to calculate the steps to be taken to achieve a specific goal, to make plans, and etc. Basically, students focus on short-term prospects and quick results.

This can be solved by improving critical and analytical thinking skills. Thinking develops in the process of learning; where appropriate, students can be involved in solving complex non-standard problems, looking for a way out of difficult situations, etc.

\subsection{Interview Results}

Examples of student responses to interview questions:

Respondent 1: The course was interesting, but it was difficult to understand how this information can be put into practice. Sometimes it was difficult to follow the lecturer and I had to go back. I got a general idea of the topic but nothing specific.

Respondent 2: The course seemed interesting to me, I would advise my friends to take it. At the same time, I did not cope with the test well. In theory, everything is clear, but in practice, problems arise.

Respondent 3: It was somewhat difficult to comprehend information in English. The course is interesting and of high quality. I think that this knowledge will help me in life despite the fact that the course was not accompanied by practice.

The majority of students (72\%) spoke positively about the quality of the course they completed; $68 \%$ of participants found this course interesting; $42 \%$ of students believe that they could benefit from the course later in life; $79 \%$ of respondents consider the topic of the course relevant; $84 \%$ of participants reported that they did not understand how to use this knowledge when dealing with life situations; 69\% of students said they had difficulties in the practical application of the knowledge gained.

Taking into account the information received from the respondents during the interview, the following recommendations for course developers can be highlighted:

- Simplify the presentation of information. To do this, diagrams, tables, and graphs can be used. Concise presentation of information contributes to better memorization and will also help students revisit the lecture material after a while. In addition, courses can be taken by people with different levels of knowledge; thus, some learners may find the teacher's explanation complicated and confusing.

- At the end / beginning of a lecture (lesson), it is necessary to provide its summary (the most important points of the lecture in the form of a table or theses). This will help learners quickly and easily remember what the lecture was about. Timecodes will enable students to quickly find the part of the lecture they need and listen to it again.

- Provide more examples of the practical application of information. Each lecture should contain 2-4 examples of the practical application of knowledge. Examples should be simple and comprehensible for learners with various levels of knowledge. As shown by the results of this study, the absence or insufficient number of examples is one of the main problems that impede effective assimilation of the course content. The lack of understanding of how the theory can be put into practice prevents students from using the information they learned in real life.

- Consider the ways to provide feedback to learners on their test results. In this case, tests should be conducted after each lecture. For example, each incorrect answer should be followed by a detailed explanation. Forums, chats, and e-mail can be used to provide feedback. Lack of communication and feedback is one of the major problems in distance learning.

- In courses aimed at a large audience, it is necessary to use the simplest language and 
immediately explain any scientific terms or provide an explanation in the form of text on the screen. It should be remembered that learners have different levels of knowledge and they could have previously studied other disciplines. For example, a philologist can take a course on the basics of programming or vice versa. Also, older people may not remember the definitions of some terms they studied in college or university.

- Pay more attention to the purpose of the course (audience, age, level of knowledge, etc.). A mixed form of courses (for example, lectures + practical classes + discussion on the forum) is suitable for engineering students. They also need a control system (attendance, individual work, tests) as young people may not have enough motivation to complete the course thoroughly and qualitatively. Working people should select courses dominated by lectures as while working, they can immediately apply theory in practice. For those who are simply interested in the topic of the course and take it on their own initiative, courses focused on the analysis of real-life examples are good option.

Today, MOOCs can be used as an additional resource to educate engineering students. Their use has a number of advantages, such as reducing the workload of teachers, ensuring a free schedule, providing an opportunity to study regardless of location, reducing costs, etc.

In engineering education, MOOCs can be used in several formats (Table 2).

Table 2. MOOCs in engineering education

\begin{tabular}{|l|l|l|}
\hline 1 & $\begin{array}{l}\text { Completing } \\
\text { additional } \\
\text { courses }\end{array}$ & $\begin{array}{l}\text { Students may be offered to take } \\
\text { additional courses, which are not } \\
\text { found in the university curriculum, } \\
\text { on the MOOC platform in order to } \\
\text { improve knowledge and broaden } \\
\text { their horizons. }\end{array}$ \\
\hline 2 & $\begin{array}{l}\text { More } \\
\text { information } \\
\text { on university } \\
\text { courses }\end{array}$ & $\begin{array}{l}\text { Students can listen to online } \\
\text { courses in order to obtain broader } \\
\text { information on any disciplines or } \\
\text { topics that are studied at university }\end{array}$ \\
\hline $\begin{array}{l}\text { Repetition of } \\
\text { information } \\
\text { from } \\
\text { university } \\
\text { courses }\end{array}$ & $\begin{array}{l}\text { Students can listen to online } \\
\text { courses in order to repeat or } \\
\text { consolidate the information they } \\
\text { learned during the lecture. It can } \\
\text { also be useful for those who } \\
\text { missed face-to-face classes. }\end{array}$ \\
\hline 4 & $\begin{array}{l}\text { Replacing } \\
\text { face-to-face } \\
\text { university } \\
\text { courses }\end{array}$ & $\begin{array}{l}\text { When circumstances require (for } \\
\text { example, distance learning, a crisis } \\
\text { situation (the Covid-19 pandemic), } \\
\text { etc.), students can complete the } \\
\text { course online }\end{array}$ \\
\hline
\end{tabular}

At this stage of the development of technologies in education, it is recommended to give preference to options No. 2 and No. 3 and not to completely abandon traditional education.

It will take universities $4.5-8$ years to completely switch from face-to-face classes to the use of MOOCs. A model of the transition of universities to the massive use of online courses is described below (Table 3).

Table 3. Model for the implementation of MOOC courses in university programs

\begin{tabular}{|c|l|c|}
\hline \multicolumn{2}{|c|}{ MOOC implementation stages } & Duration \\
\hline 1 & $\begin{array}{l}\text { The beginning of the use of MOOCs by } \\
\text { students as additional general education } \\
\text { courses. For engineering students, these } \\
\text { can be cultural studies, business ethics, } \\
\text { management }\end{array}$ & $\begin{array}{c}6 \text { months } \\
-1 \text { year }\end{array}$ \\
\hline $\begin{array}{l}\text { The introduction of MOOCs as a source } \\
\text { of additional advanced information on } \\
\text { university courses (e.g. additional } \\
\text { programming languages) }\end{array}$ & $\begin{array}{c}1-2 \\
\text { years }\end{array}$ \\
\hline 3 & $\begin{array}{l}\text { Providing an opportunity to take } \\
\text { MOOCs instead of some face-to-face } \\
\text { courses. The use of MOOCs as a source } \\
\text { of duplicate information to consolidate } \\
\text { and repeat the material. In the beginning, } \\
\text { these may be history and philosophy } \\
\text { courses. }\end{array}$ & $2-3$ years \\
\hline 4 & $\begin{array}{l}\text { Complete replacement of some } \\
\text { university courses with MOOCs. It is } \\
\text { necessary to start with non-major } \\
\text { disciplines (for example, economics, a } \\
\text { foreign language) }\end{array}$ & years \\
\hline
\end{tabular}

This model can be used by all universities in the context of all disciplines, including engineering education. However, in the course of its implementation, it is necessary to constantly monitor the effectiveness of MOOCs by testing the level of students' knowledge (tests, exams).

\section{Discussion}

As mentioned above, in a constantly changing environment, young people need to acquire knowledge not only in their area of expertise. Each student should receive basic knowledge of economics, psychology, management, and other subjects in order to be a highly qualified and competitive specialist in the labor market. According to Spanish scientists, in the modern world, it is not enough to have technical competencies and the technical education of the future should be more integrative. Moreover, in the rapidly growing economy, engineers should understand the basic principles of project management [19]. MOOCs and other online learning platforms can greatly help with this. 
Today, MOOCs are becoming increasingly popular among different categories of learners. Massive open online courses (MOOCs) have been considered an alternative to part of traditional classes in higher educational institutions while making the learning process more personalized, reducing teacher workload and the cost of implementing courses [8]. With the outbreak of the COVID-19 pandemic in 2020 , online learning has become the major way to keep learning. The first online course was launched in Canada in 2008. Today in the Russian Federation, there are three models for the introduction of online courses in higher education: (1) Introduction of MOOCs in blended learning; (2) Partial replacement of regular courses with online courses; (3) Development of an online master's degree program that is based on MOOCs [8]. Since 2020, MOOCs have gained the greatest popularity as the COVID-19 pandemic has created the need for distance learning. In addition, due to the large amount of time spent at home, many people decided to increase their level of education, which can be easily done with the help of MOOCs.

In the context of MOOCs in engineering education, scientists from the United States recommend the use of competency-based learning (CBL), which implies a pedagogical approach that focuses on measurable student outcomes [20]. The assessment of student progress is based mainly on whether he / she has acquired certain skills (competencies). Possession of such competencies implies the ability to apply the acquired knowledge in real life situations. To achieve great professional outcomes, an engineering student has to possess (1) leadership abilities; (2) teamwork skills; (3) communication skills; (4) self-reflection; (5) interdisciplinary skills; (6) recognition of a disciplinary perspective; (7) context awareness; (8) design skills [20]. This approach can help students learn to apply theoretical knowledge in practice - the skill that young people with no work experience often lack. As many participants in this study noted, putting knowledge into practice is one of the most challenging aspects of online learning.

In the course of the development of online courses, it should be borne in mind that despite the fact that they are designed for a wide audience, each student has his/her own learning style. In this regard, courses should present information so that it can be comprehended by people with various cognitive abilities. Researchers from Lithuania concluded that (1) changes in pedagogy are needed to improve student performance; (2) the main success factors in implementing mobile learning scenarios were the determination of student learning styles; identification and application of suitable learning activities, methods, goals, tools and mobile applications in accordance with the student learning styles; the use of correct sequences and sets of teaching methods when implementing mobile learning. Learning styles are categorized into visual, auditory, reading / writing, kinesthetic, and multimodal (more than two learning styles) [21].

There is an opinion that it is difficult to become an engineer by studying only remotely. Today many universities are introducing MOOCs into their curricula, but there are still many areas to be improved. Recommendations for the improvement of online engineering education: increase the quality of learning and teaching, reduce costs, increase student satisfaction, increase teacher satisfaction, provide design and maths opportunities, create better labs for online engineering education, allow students to study from anywhere, establish partnerships, use online learning technologies [22]. However, interactive learning technologies are widely used at all stages of learning. The role of news resources and websites is particularly noteworthy [23].

\section{Conclusions}

The test results showed that $61 \%$ of participants experienced some difficulties while taking the test. Thus, the performance of $19 \%$ of students was "excellent" (81-100 points); $26 \%$ demonstrated "good" results (61-80 points); the performance of $42 \%$ and $16 \%$ of respondents was rated as "satisfactory" (36-60 points) and unsatisfactory (0-35 points), respectively. The main difficulties in passing the test were the application of theoretical knowledge in practice and the insufficient number of examples in the lectures. The interviews with students showed that most of them positively assess the quality of this course. Many participants believe that the course is interesting and relevant today. Some of them are ready to recommend this course to their friends and acquaintances. However, 69\% reported that it was difficult for them to understand how to apply the information in practice.

When developing courses, it is recommended to simplify the presentation of the material, to use graphs, schemes, and tables; at the end/beginning of the lecture, to provide its brief summary in the form of a table or theses; to introduce more examples so that students understand how the information can be applied in practice; to provide feedback through forums, chats, email correspondence, etc.; to use simple language and explain all the terms found in the course materials taking into account the fact that learners can be of different ages, from different countries, and also with different levels of knowledge; to take into account the specifics of the audience the course is designed for (age, education, goals, etc.). At the same time, it is necessary to constantly monitor the effectiveness of courses by testing the knowledge of students. In the case of students, it is necessary to use control methods such as attendance records, independent work, testing as one of the reasons why young people do not 
complete online courses is the lack of motivation and control on the part of teachers and parents.

MOOCs can be used in engineering education in several ways: taking additional courses, providing additional information on university courses, repetition of information from university courses, replacing face-to-face university courses. In addition to MOOCs, it is recommended to use virtual labs and forums, where students are given more opportunities to practice their skills and communicate with peers and teachers. Today, it is not recommended to abruptly switch to online courses in major university disciplines. First, they should be used as an auxiliary learning tool and then they can replace part of faceto-face courses. As for the full transition to online courses in the future, it is necessary to take into account their effectiveness in mastering a particular specialty, as well as constantly test the knowledge of students during such training. On average, it will take universities $4.5-8$ years to completely switch from face-to-face classes to the use of MOOCs.

The research is a contribution to the study of the capabilities and quality of online platforms in engineering education and may be of interest to students, teachers, university administration, parents and all those who are interested in modern trends in education. Further research could focus on specific aspects of the operation of online learning platforms (for example, ways of providing feedback, and analyzing student data).

\section{References}

[1]. Costa, C., Hammond, M., \& Younie, S. (2019). Theorising technology in education: An introduction. Technology, Pedagogy and Education, 28(4), 395-399.

[2]. Oakley, B. A., \& Sejnowski, T. J. (2019). What we learned from creating one of the world's most popular MOOCs. NPJ science of learning, 4(1), 1-7.

[3]. Alqahtani, M. S. M., Bhaskar, C. V., Elumalai, K. V., \& Abumelha, M. (2018). WhatsApp: An Online Platform for University-Level English Language Education. Arab World English Journal (AWEJ), 9(4), 108-121.

[4]. Ang, W., Jedi, A., \& Lohgheswary, N. (2021). Factors affecting the acceptance of open learning as e-learning platform by technical course students. Journal of Engineering Science and Technology (JESTEC), 16(2), 903-918.

[5]. Mora, H., Signes-Pont, M. T., Fuster-Guilló, A., \& Pertegal-Felices, M. L. (2020). A collaborative working model for enhancing the learning process of science \& engineering students. Computers in Human Behavior, 103, 140-150.

[6]. Tadjer, H., Lafifi, Y., Seridi-Bouchelaghem, H., \& Gülseçen, S. (2020). Improving soft skills based on students' traces in problem-based learning environments. Interactive Learning Environments, 118.
[7]. Chan, K., Cheung, G., Brown, I., \& Luk, G. (2015, June). Synthesizing technology adoption and learners' approaches towards active learning in higher education. In international conference on $e$ learning (p. 66). Academic Conferences International Limited.

[8]. Radhamani, R., Divakar, A., Nair, A. A., Sivadas, A., Mohan, G., Nizar, N., ... \& Diwakar, S. (2018, September). Virtual laboratories in biotechnology are significant educational informatics tools. In 2018 International Conference on Advances in Computing, Communications and Informatics (ICACCI) (pp. 1547-1551). IEEE.

[9]. Sell, R., Rüütmann, T., \& Seiler, S. (2014). Inductive teaching and learning in engineering pedagogy on the example of remote labs. International Journal of Engineering Pedagogy (iJEP), 4(4), 12-15.

[10]. Mora, H., Ferrández, A., Gil, D., \& Peral, J. (2017). A computational method for enabling teachinglearning process in huge online courses and communities. International Review of Research in Open and Distributed Learning, 18(1), 225-246.

[11]. Staubitz, T., Klement, H., Renz, J., Teusner, R., \& Meinel, C. (2015, December). Towards practical programming exercises and automated assessment in Massive Open Online Courses. In 2015 IEEE International Conference on Teaching, Assessment, and Learning for Engineering (TALE) (pp. 23-30). IEEE.

[12]. Montes-Rodríguez, R., Martínez-Rodríguez, J. B., \& Ocaña-Fernández, A. (2019). Case Study as a Research Method for Analyzing MOOCs: Presence and Characteristics of Those Case Studies in the Main Scientific Databases. International Review of Research in Open and Distributed Learning, 20(3), 59-79.

[13]. Wilbur, K. (2016). Evaluating the online platform of a blended-learning pharmacist continuing education degree program. Medical education online, 21(1), 31832.

[14]. Bamiah, S. N., Brohi, S. N., \& Rad, B. B. (2018). Big data technology in education: Advantages, implementations, and challenges. Journal of Engineering Science and Technology, 13, 229-241.

[15]. Raoufi, K., Park, K., Khan, M. T. H., Haapala, K. R., Psenka, C. E., Jackson, K. L., ... \& Kim, K. Y. (2019). A cyberlearning platform for enhancing undergraduate engineering education in sustainable product design. Journal of Cleaner Production, 211, 730-741.

[16]. Wilson, C. (2013). User interface inspection methods: a user-centered design method. Waltham, MA:Morgan Kaufmann Publishers.

[17]. Scherrer, C. R., Butler, R. J., \& Burns, S. (2010). Student Perceptions of On-Line Education. Advances in Engineering Education, 2(2), n2.

[18]. Chiu, T. K., \& Chai, C. S. (2020). Sustainable curriculum planning for artificial intelligence education: A self-determination theory perspective. Sustainability, 12(14), 5568.

[19]. Oberlender, G. D., \& Oberlender, G. D. (1993). Project management for engineering and construction (Vol. 2). New York: McGraw-Hill. 
TEM Journal. Volume 11, Issue 1, pages 463-471, ISSN 2217-8309, DOI: 10.18421/TEM111-59, February 2022.

[20]. Cajander, Å., Daniels, M., McDermott, R., \& von Konsky, B. (2011). Assessing professional skills in engineering education. Australian Computer Science Communications, 33(2), 145-154.

[21]. Ahmed, J., Shah, K., \& Shenoy, N. (2013). How different are students and their learning styles. International Journal of Research in Medical Sciences, 1(3), 212-215.
[22]. Bourne, J., Harris, D., \& Mayadas, F. (2005). Online engineering education: Learning anywhere, anytime. Journal of Engineering Education,94(1), 131-146.

[23]. Lee, S. H., Magjuka, R., Liu, X., \& Bonk, C. J. (2006). Interactive technologies for effective collaborative learning. International Journal of Instructional Technology and Distance Learning, 3(6), 17-32. 